\title{
Comparison of Preoperative, Operative and Postoperative Variables in Asymptomatic or Minimally Symptomatic Patients to Severely Symptomatic Patients Three Years After Coronary Artery Bypass Grafting: Analysis of 423 Patients
}

\author{
PIM J. de FEYTER, MD, PATRICK W. SERRUYS, MD, RONALD W. BROWER, PhD, \\ MARCEL van den BRAND, MD, HARALD J. ten KATEN, BSc, \\ PAUL G. HUGENHOLTZ, MD, and EGBERT BOS MD
}

\begin{abstract}
During a follow-up period of 3 years, among a consecutive series of 423 patients who gave informed consent for recatheterization both 1 and 3 years after coronary artery bypass grafting, the incidence of severely symptomatic patients with New York Heart Association class III or IV was $19 \%$ ( 79 of 423). The predictive value of approximately 80 clinical, angiographic and perioperative variables was too low to be of clinical value. Adverse clinical outcome was associated with a high closure rate of
\end{abstract}

the grafts. Forty-six percent of the patients could not undergo reoperation because of unsuitable coronary anatomy. With intensive medical therapy half of these patients improved to functional class I or II, while of those patients who were reoperable $32 \%$ improved to class I or II with intensive pharmacologic treatment instead of reoperation. The nonresponders underwent reoperation, which resulted in improvement of symptoms to functional class I or II in most (83\%). (Am J Cardiol 1985;55:362-366)
In this report we focus on patients who became severely symptomatic after coronary artery bypass grafting (CABG) during 3 years of follow-up. The following questions were posed: What is their incidence? Can an adverse postoperative outcome be predicted from preoperative or perioperative variables? What are the explanatory factors for this adverse outcome? What is the reoperability rate, how were these patients actually managed and what was their clinical outcome?

\section{Methods}

From January 1976 to December 1979, a consecutive series of 637 patients underwent CABG at the Thoraxcenter, Rotterdam. All patients had symptoms before operation despite adequate medical treatment. The complaints were stable or unstable angina. Patients with coexisting valvular or con-

From the Thoraxcenter, Erasmus University, and Interuniversity Cardiology Institute, Rotterdam, The Nethcrlands. Manuscript receivcd July 18, 1984; revised manuscript received October 24, 1984, accepted October 25, 1984.

Address for reprints: Pim J. de Feyter, MD, Dijkzigt ziekenhuis, Thoraxcentrum Bd428, Dr. Molewaterplein 40, 3015 GD Rotterdam, The Netherlands. genital heart disease, those who had undergone left ventricular (LV) aneurysmectomy, surgery for dysrhythmias, and those with a life expectancy of less than 5 years because of other serious disease were excluded. Four hundred twenty-three patients $(66 \%)$ agreed to undergo recatheterization at 1 and 3 years after operation, irrespective of their postoperative complaints. These patients constitute the study population. Before CABG, $34 \%$ of the patients did not agree to undergo 2 postoperative catheterizations. On the basis of clinical data (age, sex, severity of symptoms and previous myocardial infarction $[\mathrm{MI}]$ ) and preoperative angiographic data (severity and extent of coronary artery disease (CAD) and LV function), both groups (no informed consent vs informed consent) were comparable.

Of the 423 patients who formed the study population, 3 died during operation. During a follow-up of 3 years, 79 patients have become severely symptomatic and 341 patients have had no or mild symptoms. (Fig. 1).

Follow-up and management: All patients were seen every 6 months in the outpatient department over the 3-year period. Severe symptoms (persistent or recurrent) were defined as angina pectoris of New York Heart Association (NYHA) functional class III or IV severity. All but 1 of the 79 severely symptomatic patients could be evaluated with angiography. Reoperability was assessed in joint discussion between the 
cardiac surgeons and cardiologists. After assessment of reopcrability, all severely symptomatic patients were initially treated with intense pharmacologic therapy. The patients who had no adequate response to this treatment and those who desired a reoperation (a minority) underwent reoperation. Intensive pharmacologic therapy consisted of nitrates (shortand long-acting) and $\beta$-adrenergic agents, inasmuch as calcium antagonists were not available before 1979 .

Of the 341 patients with no or mild symptoms despite initial agreement for recatheterization, 276 actually underwent this procedure at 1 year and 158 at 3 years. The patients who did not undergo recatheterization refused upon reconsideration. Clinically available information indicated that the patients who refused recatheterization did not differ from those who consented.

Coronary angiography: Selective coronary angiography was performed in multiple projections including hemiaxial views. The degree of luminal narrowing was coded according to the guidelines of the American Heart Association. ${ }^{1}$ The degree of luminal narrowing was assessed visually and scored as less than $50 \%, 50$ to $89 \%, 90$ to $99 \%$, and $100 \%$. The bypass grafts were infused selectively with contrast medium to establish patency.

The severity of the underlying CAD before and after CABG was quantified by the coronary score system developed by Leaman and Brower and their co-workers. ${ }^{2,3}$ This coronary score represents the combined effect of the disease in a segment of the coronary artery weighted according to the significance of that vessel. A score of 0 would indicate no obstructive disease, whereas the higher the score, the greater the severity of disease.

In deriving the postoperative coronary score, a vessel segment supplied by a graft was considered to take over the disease factor, if any, of the graft, provided there was no other total occlusion distal to this segment and proximal to the graft anastomose. This postoperative score represents remaining $\mathrm{CAD}$, taking into account disease in the native system as well as closure of grafts.

From this principle, 2 additional postoperative scores could be derived: the coronary score corrected for CABG immediately after surgery and during follow-up, assuming all grafts patent and normal, representing remaining disease in the native coronary system that could not be effectively bypassed, and the coronary score corrected for CABG assuming all grafts closed (or not placed), representing severity of disease in the total native coronary system during follow-up.

Statistical analysis: Univariate statistical analysis was performed using either the chi-square test or Student $t$ test when appropriate using double-sided distributions. Multivariate discriminant function stepdown function analysis was performed with program P7M of the BMDP statistical package.

\section{Results}

Characteristics of the population: Of the 423 patients, $93 \%$ were men; mean age was $51.6 \pm 7.1$ years. Sixty-eight percent had a previous MI. Sixteen percent of the patients had 1-vessel, $27 \%$ had 2 -vessel, $50 \%$ had 3 -vessel and $6 \%$ left main CAD. Sixty percent of the patients had an ejection fraction greater than $0.50,24 \%$ between 0.30 and 0.50 , and $2 \%$ less than 0.30 ; the ejection fraction was unknown in $13 \%$. The perioperative mortality was $0.7 \%$ ( 3 of 423 patients). During a follow-up of 3 years the incidence of severely symptomatic patients was $19 \%$ (79 of 420 patients) (Fig. 1).

Predictability of postoperative clinical outcome: The most important pre- and perioperative clinical and angiographic variables are presented in Tables I, II and III. Multivariate analysis showed that 3 variables had independent predictive value for postoperative severe angina: a low preoperative coronary scorc, performance of endarterectomy, and absence of previous MI. Together, these 3 variables correctly predicted $60 \%$ of the patients with adverse clinical outcome and $62 \%$ of the patients with no or mild symptoms.

Explanatory factors for severe symptoms after bypass surgery: The results of pre-, peri- and postoperative angiographic variables arc shown in Table IV and Figure 2. An adverse clinical outcome is associated with a higher corrected coronary score, caused by a lower patency rate. There were no differences in preoperative extent of CAD, the number of nonbypassed stenoses, or progression of disease in the native coronary circulation.

Reoperability, management and clinical outcome: Reoperability was assessed in 70 patients; $46 \%$ of them were unable to undergo reoperation for technical reasons. The actual management and resulting clinical outcome are shown in Figure 3. Intensive pharmacologic treatment was offered to all patients who could not undergo reoperation.

\section{Discussion}

Many patients suffer from angina pectoris after CABG. During a follow-up study of 75 unselected patients, Campeau et al $^{4}$ found a recurrence rate of angina pectoris of $38 \%$ at 1 year after operation, $45 \%$ at 3 years and $63 \%$ at 7 years. In a follow-up study of 748 patients for 5 to 94 months, Cameron et al ${ }^{5}$ found a recurrence rate of angina of $21 \%$ at 1 year to $37 \%$ at 6 years. The severity of angina was generally milder than before operation. The European Coronary Surgery Study 6 reported a postoperative recurrence rate of angina of $42 \%$ at 1 year and $51 \%$ at 3 years. In approximately half of the patients the symptoms were unchanged or even

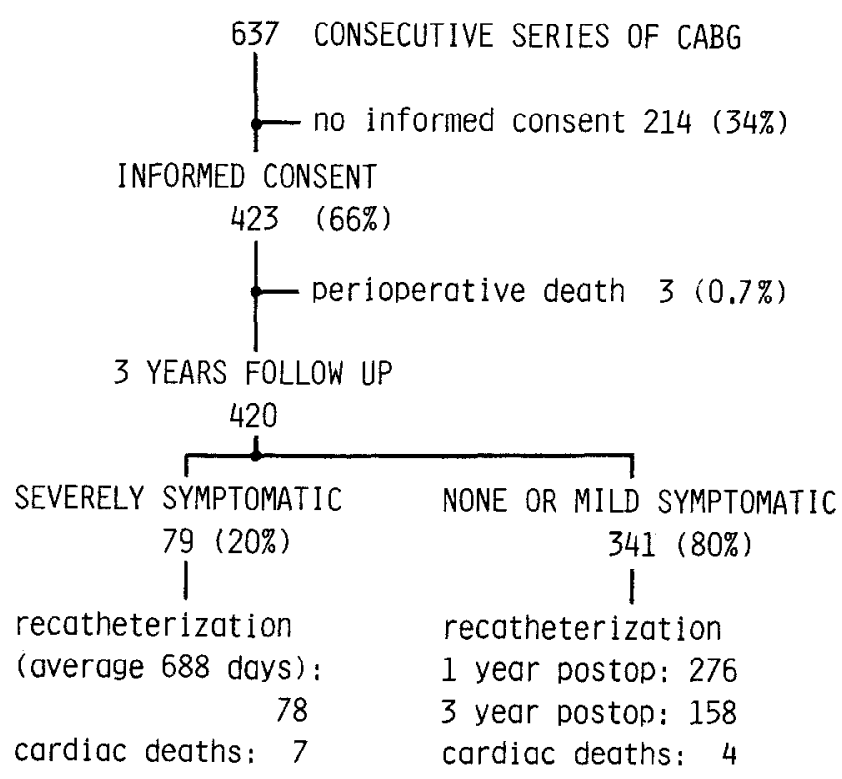

FIGURE 1. Incidence of patients with severe symptoms during 3 years follow-up after coronary artery bypass surgery (CABG). 
TABLE I Predictive Value of Clinical Variables

\begin{tabular}{|c|c|c|c|}
\hline Variable & $\begin{array}{c}\text { Severely } \\
\text { Symptomatic } \\
\text { Patients } \\
(n=79) \\
n(\%)\end{array}$ & $\begin{array}{c}\text { No or } \\
\text { Mild } \\
\text { Symptoms } \\
(n=340) \\
n(\%)\end{array}$ & $p$ Value \\
\hline Men & $73(92)$ & $316(93)$ & NS \\
\hline Age $>53$ yr & $35(44)$ & $171(50)$ & NS \\
\hline $\begin{array}{l}\text { History of MI } \\
\text { Cigarette smoker }\end{array}$ & $46(58)$ & $240(71)$ & $\begin{array}{l}\text { NS } \\
\text { NS }\end{array}$ \\
\hline $\begin{array}{l}\text { Cigarette smoker } \\
\text { Cerebrovascular disease }\end{array}$ & $\begin{array}{l}77(97) \\
21(27)\end{array}$ & $\begin{array}{r}295(87) \\
80(24)\end{array}$ & NS \\
\hline Diastolic $\mathrm{BP}>100 \mathrm{~mm} \mathrm{Hg}$ & $33(42)$ & $101(30)$ & NS \\
\hline Diabetes mellitus & $6(8)$ & $17(5)$ & NS \\
\hline Family history of CAD & $41(52)$ & $178(52)$ & NS \\
\hline 4th heart sound & $17(22)$ & $43(13)$ & NS \\
\hline CT ratio >0.5 & $40(51)$ & $167(49)$ & NS \\
\hline $\begin{array}{l}\text { Total serum cholesterol } \\
>7.0 \mathrm{mmol} / \mathrm{liter}\end{array}$ & $35(44)$ & $146(43)$ & NS \\
\hline $\begin{array}{l}\text { Serum triglycerides } \\
>2.5 \mathrm{mmol} / \text { liter }\end{array}$ & $22(28)$ & $91(27)$ & NS \\
\hline
\end{tabular}

$p$ value: univariate analysis, $\chi^{2}$ test.

$\mathrm{BP}=$ blood pressure; $\mathrm{CAD}=$ coronary artery disease; $\mathrm{CT}=$ cardiothoracic; $\mathrm{Ml}=$ myocardial infarction; $\mathrm{NS}=$ not significant

\section{TABLE III Predictive Value of Perioperative Variables}

\begin{tabular}{|c|c|c|c|}
\hline Variable & $\begin{array}{c}\text { Severely } \\
\text { Symptomatic } \\
\text { Patients } \\
(n=79) \\
n(\%)\end{array}$ & $\begin{array}{c}\text { No or } \\
\text { Mild } \\
\text { Symptoms } \\
(n=340) \\
n(\%)\end{array}$ & $p$ Value \\
\hline $\begin{array}{l}\text { Multiple grafts placed } \\
\text { Lowest flow per graft }<45 \mathrm{ml} \\
\text { Total graft flow }>50 \mathrm{ml} \\
\text { Coronary endarterectomy } \\
\text { Duration ECC }>110 \mathrm{~min} \text {. } \\
\text { Duration ACC }>35 \mathrm{~min} \text {. } \\
\text { Perioperative infarction } \\
\text { IABP assistance }\end{array}$ & $\begin{array}{l}69(87) \\
49(62) \\
64(81) \\
39(49) \\
36(46) \\
37(47) \\
4(5) \\
3(4) \\
\end{array}$ & $\begin{array}{l}280(82) \\
211(62) \\
292(86) \\
126(37) \\
155(46) \\
138(41) \\
18(5) \\
24(7)\end{array}$ & $\begin{array}{l}\text { NS } \\
\text { NS } \\
\text { NS } \\
0.05 \\
\text { NS } \\
\text { NS } \\
\text { NS } \\
\text { NS }\end{array}$ \\
\hline
\end{tabular}

$p$ value: univariate analysis, $\chi^{2}$ test. $A C C=$ aortic cross-clamping time; $\mathrm{ECC}=$ extracorporeal circulation; IABP = intraaortic balloon pumping; $N S=$ not significant.
TABLE II Predictive Value of Preoperative Angiographic Variables

\begin{tabular}{|c|c|c|c|}
\hline Variable & $\begin{array}{c}\text { Severely } \\
\text { Symptomatic } \\
\text { Patients } \\
(n=79) \\
n(\%)\end{array}$ & $\begin{array}{c}\text { No or } \\
\text { Mild } \\
\text { Symptoms } \\
(n=340) \\
n(\%)\end{array}$ & $p$ Value \\
\hline $\begin{array}{l}\text { Pain during APST } \\
\text { LVEDP }>13 \mathrm{~mm} \mathrm{Hg} \\
\text { EF >0.60 } \\
\text { 3-vessel CAD } \\
\text { Multivessel CAD } \\
\text { Preoperative } \\
\quad \text { coronary score }>15\end{array}$ & $\begin{array}{l}36(46) \\
35(44) \\
38(48) \\
43(54) \\
66(84) \\
23(29)\end{array}$ & $\begin{array}{l}158(46) \\
183(54) \\
139(41) \\
208(61) \\
291(86) \\
138(41)\end{array}$ & $\begin{array}{l}\text { NS } \\
\text { NS } \\
N S \\
N S \\
N S \\
<0.05\end{array}$ \\
\hline
\end{tabular}

p value: univariate statistics, $\chi^{2}$ test.

APST = atrial pacing stress test; $\mathrm{CAD}=$ coronary artery disease; $\mathrm{EF}=$ ejection fraction; LVEDP = left ventricular end-diastolic pressure; NS $=$ not significant.

worse than before operation. Rahimtoola ${ }^{7}$ reported that CABG reduced symptoms in 76 to $90 \%$ of patients; 33 to $55 \%$ became asymptomatic, 5 to $6 \%$ showed deterioration of symptoms after surgery, and angina recurred at an annual rate of 2 to $4 \%$.

Laird-Meeter et $\mathrm{al}^{8}$ studied 1,041 patients with a follow-up of 1 to 10 years (mean 3.5). The incidence of postoperative angina pectoris at 1 year was $30 \%$, at 3 years $46 \%$ and at 8 years $50 \%$. However, $89 \%$ of these symptomatic patients felt themselves improved by surgery. In this study, approximately $40 \%$ of the operated patients reported angina pectoris during a follow-up period of 3 years, which is in agreement with the studies cited earlier. Half of these patients had severe angina pectoris. Thus the incidence of severe symptomatic patients with NYHA class III to IV during a 3 -ycar follow-up was 19\%; most of the patients had class III symptoms.

Predictability of clinical outcome after bypass surgery: Obviously, patient management could be
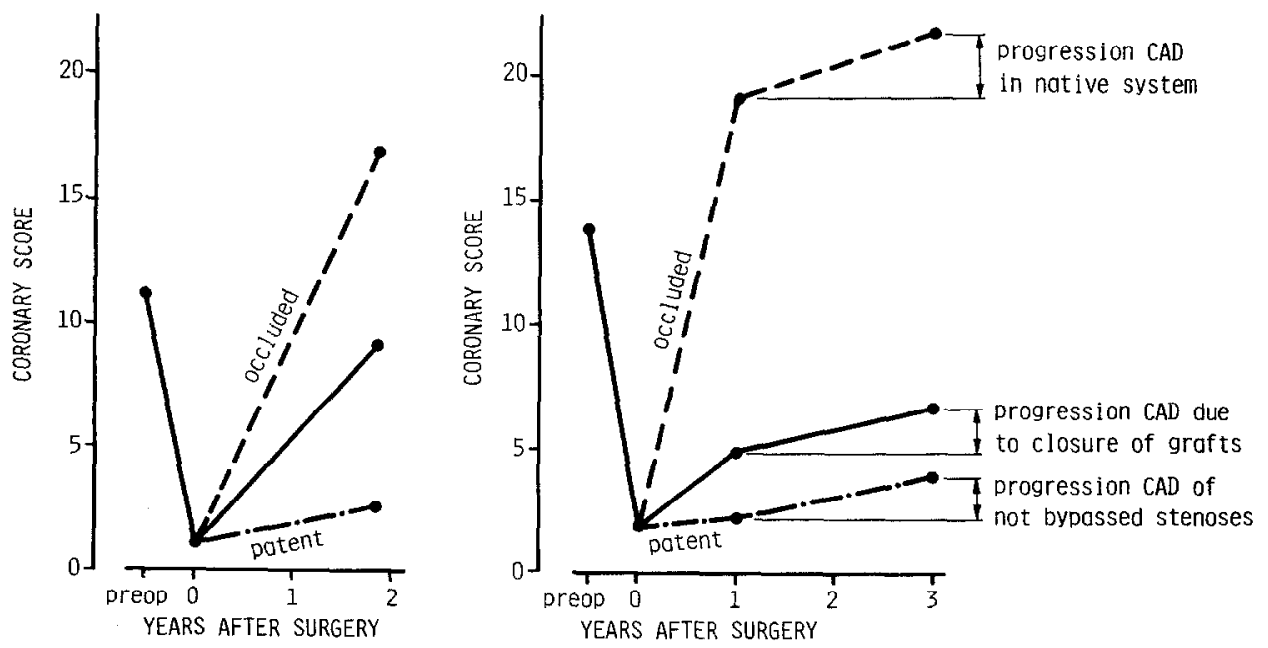

FIGURE 2. Progression of coronary artery disease (CAD) in severely symptomatic patients (A) and asymptomatic or mildly symptomatic patients (B). $\mathrm{CABG}=$ coronary artery bypass graft surgery.

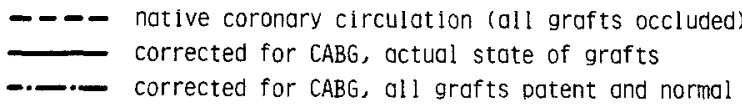


TABLE IV Explanatory Factors for Severe Symptoms After Coronary Artery Bypass Grafting

\begin{tabular}{|c|c|c|c|}
\hline Variable & $\begin{array}{c}\text { Severely } \\
\text { Symptomatic } \\
(n=79)\end{array}$ & \multicolumn{2}{|c|}{$\begin{array}{l}\text { No or Mild Symptoms } \\
\qquad(\mathrm{n}=340)\end{array}$} \\
\hline \multicolumn{4}{|c|}{ Preoperative } \\
\hline $\begin{array}{l}\text { LV end-diastolic pressure } \\
\text { Ejection fraction } \\
\text { Preoperative coronary score } \\
\text { Perioperative coronary score (all grafts assumed } \\
\quad \text { open) } \\
\text { No. of grafts placed }\end{array}$ & $\begin{array}{l}17 \pm 8 \\
0.59 \pm 0.11 \\
11.3 \pm 7.7 \\
1.1 \pm 2.1 \\
2.3 \pm 0.8\end{array}$ & \multicolumn{2}{|c|}{$\begin{array}{l}17 \pm 6 \quad(\mathrm{NS}) \\
0.58 \pm 0.11(\mathrm{NS}) \\
14.2 \pm 7.2(\mathrm{p}<0.05) \\
1.8 \pm 3.0 \text { (NS) }\end{array}$} \\
\hline \multicolumn{4}{|c|}{ Postoperative } \\
\hline $\begin{array}{l}\text { No. of recatheterizations } \\
\text { Follow-up after surgery } \\
\text { (range, SD) (days) }\end{array}$ & $\begin{array}{c}78 \\
688 \text { days } \\
20-1533,425\end{array}$ & $\begin{array}{c}276 \\
1 \text { year } \\
271-776,66\end{array}$ & $\begin{array}{c}162 \\
3 \text { years } \\
912-1462,84\end{array}$ \\
\hline $\begin{array}{l}\text { Postoperative coronary score } \\
\text { Native coronary circulation } \\
\text { Corrected score (grafts in actual state) } \\
\text { Corrected score (grafts assumed open) } \\
\text { Patency rate grafts }\end{array}$ & $\begin{array}{l}17 \pm 9 \\
9.2 \pm 7.8 \\
2.7 \pm 4.3 \\
55 \%\end{array}$ & $\begin{array}{l}19 \pm 8 \text { (NS) } \\
5.0 \pm 5.7(\mathrm{p}<0.001) \\
2.3 \pm 3.6(\mathrm{NS}) \\
82 \%(\mathrm{p}<0.0001)\end{array}$ & $\begin{array}{l}22 \pm 9(p<0.01) \\
6.8 \pm 7.5(p<0.05) \\
4.1 \pm 4.9(N S) \\
80 \%(p<0.0001)\end{array}$ \\
\hline
\end{tabular}

Values are mean + standard deviation.

$\mathrm{p}$ value: univariate statistics, unpaired $t$ test, no symptoms vs symptoms.

$\mathrm{NS}=$ not significant; $\mathrm{SD}=$ standard deviation.

improved if adverse postoperative outcome could be predicted. Of the approximately 80 analyzed clinical, angiographic and perioperative variables, 3 variables were associated with clinical outcome, but classified outcome correctly in only $61 \%$ of all patients. This predictive value is too low to be clinically useful.

Explanatory factors for severe symptoms after bypass surgery: Postoperative angina pectoris is often related to incomplete revascularization, early closure of grafts or progression of coronary sclerosis in the native coronary arteries. ${ }^{4,9-13}$ Adverse clinical outcome was associated with a higher attrition rate of grafts, whereas no differences were found in the rate of incomplete revascularization or progession of $\mathrm{CAD}$ in the native system of patients with no or mild symptoms compared with those who had severe symptoms. We do not know the reason for this higher graft closure rate in the symptomatic patients; although a low intraoperative graft flow, performance of endarterectomy and perioperative complications are associated with a higher graft attrition rate, ${ }^{14}$ these findings do not imply that all these patients became scvercly symptomatic, as was the endpoint in this study.

Reoperability rate, management and clinical outcome of severely symptomatic patients: The reoperability rate of severely symptomatic patients was about $50 \%$. In the remainder, coronary anatomy was unsuitable for further surgery. With intensive medical treatment, $50 \%$ of these patients improved to NYHA class I or II. Most of the reoperable patients were initially offered intense medical treatment before repeat surgery was advised; with such treatment about onethird of the patients improved to class I or II symptoms. The others underwent reoperation, after which $83 \%$ improved to class I, II or III.

\section{References}

1. American Heart Association, Council on Cardiovascular Surgery. Report of the Ad Hoc Committee for Grading of Coronary Artery Disease: a reporting of the Ad Hoc Committee for Grading of Coronary Artery Disease: a reporting
system on patients evaluated for coronary artery disease. Dallas: American
FIGURE 3. Reoperability rate, management and clinical course of patients with severe symptoms after bypass surgery.
SEVERELY SYMPTOMATIC PATIENTS (79)

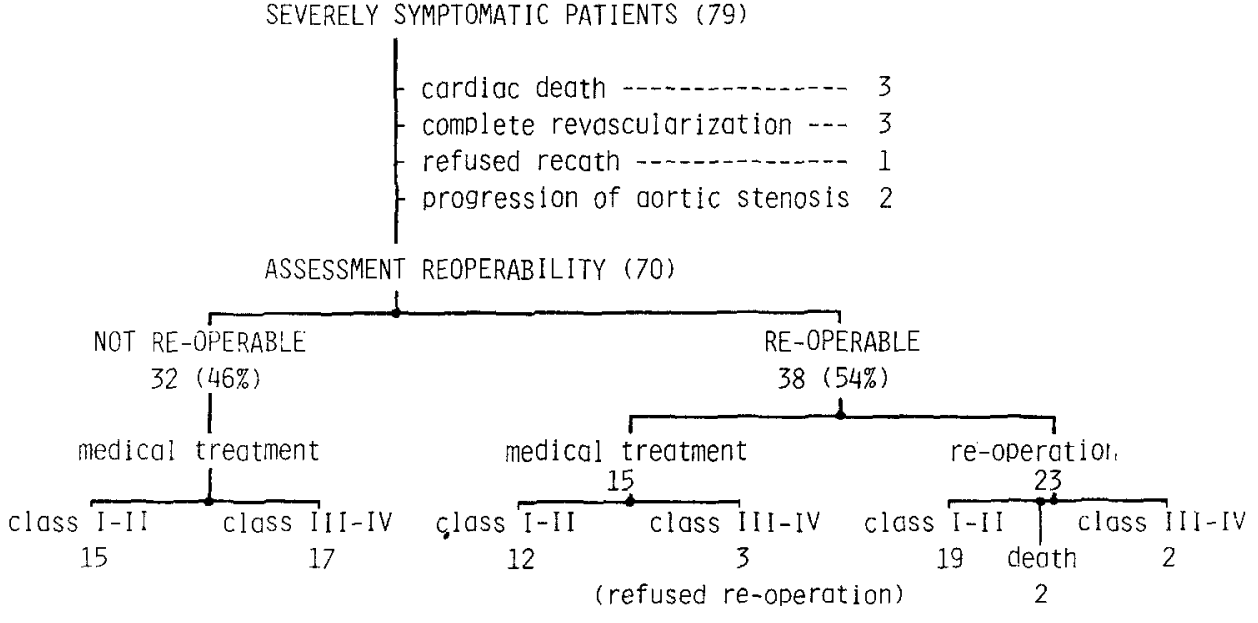


Heart Association document 73-315-A. Circulation 1975;51:7-40.

2. Leaman DM, Brower RW, Meester GT, Serruys PW, van den Brand M. Coronary artery atherosclerosis: severity of the disease, severity of angina pectoris, and compromised left ventricular function. Circulation 1981 63:285-292.

3. Brower RW, Laird-Meeter K, Serruys PW, Meester GT, Hugenholtz PG Long term follow up after coronary artery bypass graft surgery. Progression and regression of disease in native coronary circulation and bypass grafts Br Heart J 1983;50:42-47.

4. Campeau L Lesperance J, Hermann J, Corbara F, Grondln CM, Bourassa MG. Loss of improvement of angina between 1 and 7 years after coronary bypass surgery. Circulation 1979;60:suppl 1:1-1-1-5.

5. bypass surgery. Circulation 1979;60:suppl 1:1-1-l-5.

. Cameron A, Kemp HG, Shimomura S, Santilli E, Green GE, Hutchinson JE, Mekhjian HA. Aorto coronary bypass surgery. A 7-year follow up. Circulation 1979;60:suppl 1:1-9-1-13

6. Prospective Randomized Study of Coronary Artery Bypass Surgery in Stable Angina Pectoris. Second interim report by the European Coronary Surgery Study Group. Lancet 1980;2:491-495.

7. Rahimtoola SH. Coronary bypass surgery for chronic angina-1981. A perspective. Circulation 1982;65:225-241.

8. Lalird-Meeter K, ten Katen HJ, Brower RW, van den Brand MJBM, Serruys
PW, Haalebos MMP, Bos E, Hugenholtz PG. Angina Pectoris, 1 to 10 years after aorto-coronary bypass surgery. Eur Heart J 1983;4,678-686.

9. Culliford AT, Girdwood RW Isom OW Krauss KR, Spencer FC. Angina following myocardial revascularization. J Thorac Cardiovasc Surg 1975 . following my

10. Seides SF, Borer JS, Kent KM, Rosing DR, McIntosh CL, Epstein SE. Long term anatomic fate of coronary-artery bypass grafts and functional status of patients five years after operation. N Engl J Med 1978;298:12131217.

11. Loop FD, Cosgrove DM, Kramer JR, Lytle BW, Taylor PC, Golding L, Groves LK. Late clinical and arteriographic results in 500 coronary artery reoperations. J Thorac Cardiovasc Surg 1981;81:675-685.

12. Bourassa MG, Campeau L Lesperance J, Grondin CM. Changes in grafts and coronary arteries after saphenous vein aorto-coronary bypass surgery: results at repeat angiography. Circulation 1982;65:suppl |l:II-90-1I-97.

13. Lawrie GM, Morris GC, Chapman DW, Winters JL, Lie JT. Patterns of patency of 596 vein grafts up to seven years after aorto coronary bypass. $\mathrm{J}$ Thorac Cardiovasc Surg 1977;73:443-448.

14. Shark WM, Kass RM. Repeat myocardial revascularization in coronary disease therapy: considerations of primary bypass failures and success of second graft surgery. Am Heart $J 1981 ; 102: 303-307$. 